\title{
STABILITY OF WATER SOLUBLE ANTIOXIDANTS IN CATTLE BLOOD COLLECTED IN DIFFERENT MEDIA
}

\author{
F. M. F. Hayajneh ${ }^{1^{*}}$ and N. A. Abdellatif ${ }^{2}$ \\ ${ }^{1}$ College of Pharmacy, Department of pharmacology, Al Taif University, Kingdom of Saudi Arabia \\ ${ }^{2}$ Faculty of Pharmacy, Department of Clinical Pharmacy, Al Taif University, Kingdom of Saudi Arabia
}

\begin{abstract}
The study was carried out to compare between different media used to preserve blood samples taken in the field, and to determine in which of these media is the water soluble antioxidative capacity (ACW) is most stable, because sometimes it takes long time for the blood samples taken in the field to be transported to the laboratory where different biochemical tests are made, in this time during transport the samples underly many factors that have an effect on the content of the samples under study like light, temperature, and time itself. Also the effect of centrifugation was tested to see weather direct or delayed centrifugation has an effect on the water soluble antioxidative capacity of the blood.There are no studies related directly to choosing the proper medium for preserving blood samples when the water soluble antioxidative capacity will be tested. In this study the highest values were achieved using serum samples, and this was the reason why serum tubes were chosen in the rest of the study.In this study four different media were tested, and compared with each other, the measured ACW values in the different media were arranged as follows:serum $>\mathrm{NaF}-\mathrm{LiH}>\mathrm{LiH}>\mathrm{EDTA}$.
\end{abstract}

Key words: antioxidant, free radical, serum, lithium heparin, anticoagulant

\section{INTRODUCTION}

Antioxidants are molecules that can easily and harmlessly give up an electron. Nature produces an array of antioxidants to prevent free radical formation or to limit their damaging effects in cells. These include enzymes to decompose peroxides, proteins to bind transition metals, and other compounds that scavenge free radicals. The most important biological antioxidants are vitamins A, C, E and selenium, a key component of glutathione peroxidase. Vitamin A and or other carotenoids are abundant in many animal feeds and inexpensive to supplement. Vitamin $\mathrm{C}$ is produced naturally in the tissues of farm animals and thus is not routinely supplemented (Berger, 2003).

These antioxidants are found in plasma and in other extracellular fluids, in intracellular fluids, lipoproteins, and membranes. The non-enzymatic low-molecular weight antioxidants can be further subdivided into water-soluble and lipid-soluble antioxidants. Examples of water-soluble antioxidants are ascorbic acid, glutathione, and uric acid (Bernabucci et al., 2005).

Both water-soluble antioxidants and fat-soluble antioxidants are needed because free radicals are found in both areas of the cells. A free radical located in a cell membrane cannot be neutralized by an antioxidant located in the cytosol. Known antioxidant pathways suggest that the requirements of antioxidant nutrients are interrelated. A deficiency of one antioxidant may increase the requirement of another nutrient. However, a deficiency of a particular antioxidant nutrient cannot be alleviated fully by another nutrient (Weiss, 2005).

Vitamin C, Uric Acid and glutathione are among the most widely studied antioxidants. Vitamin C is considered the most important water-soluble antioxidant in extracellular fluids. Glutathione, an important water-soluble antioxidant, is synthesized from the amino acids glycine, glutamate, and cysteine. Glutathione directly quenches ROS such as lipid peroxides, and also plays a majorrole in xenobiotic metabolism (Percival, 1996).The most important antioxidant is ascorbic acid (AA). The compound remains an interesting topic of much scientific research even though it was discovered many years ago. The ability of AA to minimize harmful environmental influence on the metabolism is of special interest. AA protects DNA of the cells from the free radicals damage, prevents infections by strengthening cell membranes, and helps protecting phagocytic cells from oxidative damage (Kleczkowski et al., 2005).Glutathione is among the most important antioxidants in biological systems, it is a tripeptide composed of the amino acids glutamate, cysteine, and glycine (Cadenas and Packer, 2002). Glutathione is mainly synthesized de novo within the liver (Cadenasand Packer, 2002).

*Corresponding e-mail address: firashope@yahoo.com 


\section{F. M. F. Hayajneh and N. A. Abdellatif}

Its reduced form is a tripeptide (GSH) that has variable tissue distribution, it has a low molecular weight and is the most abundant thiolic compound in mammalian cells (Powers and Lennon, 1999). Due to its chemical properties, it reacts with several oxidant compounds, such as hydrogen peroxide, superoxide, hydroxyl and reactive carbon species (Yu, 1994; Halliwell and Gutteridge, 1984).It can also reduce tocopheroxyl free radicals and dehydroascorbate to their original forms.

It was proposed that uric acid may be an important antioxidant in humans. This hypothesis is supported by the ability of uric acid to scavenge hydroxyl radicals, singlet oxygen, and oxo-heme oxidants (Kirk and Ronald, 1987). Uric acid has been traditionally considered as an end product of purine metabolism, its function as an intra- and extracellular biological antioxidant has been accepted recently. It seems to prevent vitamin C oxidation and forms complexes with $\mathrm{Fe}$ and $\mathrm{Cu}$ (Ricardo, 2002).During the last 3 decades, much attention has been focused on determining the mechanisms by which antioxidants protect cells from oxygen radicals and other activated oxygen species (Maples and Mason, 1988). Several methodshave been developed to assess the total antioxidant capacity of human Serum or plasma because of the difficulty in measuring each antioxidant component separately and the interactions among different antioxidant components in the Serum or plasma (Cao and Prior, 1998).

\section{Materials and Methods}

The method used for the determination of the water soluble antioxidative capacity in this study is the method described by Popov and Lewin (1994) which is a method for testing and quantification of non-enzymatic antioxidants, such as ascorbic acid and uric acid and of polycomponent systems like plasma. This system is based on a photochemical generation of free radicals combined with their chemiluminescent detection.

For the determination of the water soluble antioxidative capacity the following reagents were used

- Reagent 1: ACW-Diluent (sample solvent).

- Reagent 2: Reaction buffer.

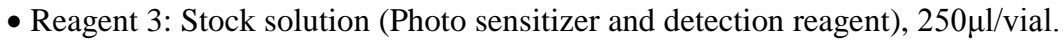

- Reagent 4: Calibration standard for the quantification of water soluble antioxidants in equivalents of ascorbic acid.

\section{Measuring principle}

Free radicals are being produced by irradiation of a photosensitizer (dye) substance. These radicals are partially eliminated from the sample after they react with the antioxidants normally present in the sample, the remaining radicals in the measuring cell cause luminescence to the detector substance. In this way the antioxidant capacity of the sample is being determined. Quantification of the antioxidative capacity of the sample is determined by comparison with the standard (calibration curves are constructed using ascorbic acid in case of ACW measurement, and trolox in case of ACL measurement).

\section{Results}

In this study different mediums in which blood samples are preserved were tested, the stability of the watersoluble antioxidative capacity was tested in different media under room temperature conditions.

The four media used are:

- Serum tubes (without anticoagulant).

- Tubes containing ethylenediaminetetraacetic acid (EDTA) as anticoagulant.

- Tubes containing sodium fluoride $(\mathrm{NaF})$ and lithium heparin as anticoagulant.

- Tubes containing lithium heparin $(\mathrm{LiH})$ an anticoagulant.

The blood samples were taken, kept in the refrigerator for 30 minutes, centrifuged for 10 minutes, $4000 \mathrm{R} / \mathrm{min}$ and then tested under room temperature conditions $\left(+25 \mathrm{C}^{\circ}\right)$ in one hour interval in order to determine the stability of the water-soluble antioxidative capacity. The first measurement was done after one hour because of technical reasons (it took sometime time withdraw the samples, transport them to the laboratory, and to centrifuge the samples which was sometimes repeated more than one time). 
As seen in (Table 1) the ACW values in the Serum tubes were the highest among the four media used, and the lowest were achieved using EDTA containing tubes. The ACW values in NaF-LiH containing tubes were higher than in $\mathrm{LiH}$ containing tubes.

Table1. Comparison between the ACW values in the different media/original values after 1 hour

\begin{tabular}{|lllll|}
\hline Medium & $\mathrm{n}$ & Mean Value & $\mathrm{s}$ & $\mathrm{s}_{\mathrm{x}}$ \\
\hline Serum & 10 & 13.3 & 4.27 & 1.35 \\
EDTA & 10 & 7.0 & 2.87 & 0.91 \\
NaF-LiH & 10 & 10.1 & 3.49 & 1.10 \\
LiH & 10 & 8.0 & 2.61 & 0.83 \\
\hline
\end{tabular}

* Dependant variable ACW $(\mu \mathrm{g} / \mathrm{ml}) .{ }^{*} \mathrm{n}$ : number of tested samples, ${ }^{*}$ Mean value, standard deviation, standard failure of the original values was calculated

By comparing the ACW values it is noticed that they are arranged as follows: Serum $>\mathrm{NaF}-\mathrm{LiH}>\mathrm{LiH}>\mathrm{EDTA}$ where the difference between the ACW values is statistically significant when compared with the other media (Table 2).

Table 2. Comparison between ACW values in the different media after 1 hour

\begin{tabular}{|c|c|c|c|c|c|c|c|}
\hline \multirow[t]{2}{*}{ Medium (I) } & \multirow[t]{2}{*}{ Medium (J) } & \multirow[t]{2}{*}{$\mathrm{n}$} & \multirow[t]{2}{*}{ Mean difference $(\mathrm{I}-\mathrm{J})$} & \multirow[t]{2}{*}{$\mathrm{s}_{\mathrm{x}}$} & \multirow[t]{2}{*}{$\mathrm{p}$} & \multicolumn{2}{|c|}{$\begin{array}{l}95 \% \text { Confidence } \\
\text { interval }\end{array}$} \\
\hline & & & & & & Lower limit & Upper limit \\
\hline \multirow{4}{*}{ Serum } & EDTA & 10 & 6.3 & 1.42 & 0.002 & 3.06 & 9.49 \\
\hline & $\mathrm{NaF}$ & 10 & 3.1 & 0.95 & 0.009 & 0.99 & 5.28 \\
\hline & $\mathrm{LiH}$ & 10 & 5.3 & 1.38 & 0.004 & 2.14 & 8.36 \\
\hline & Serum & 10 & & & & & \\
\hline \multirow[t]{3}{*}{ EDTA } & $\mathrm{NaF}$ & 10 & -3.1 & 0.93 & 0.008 & -5.25 & -1.03 \\
\hline & $\mathrm{LiH}$ & 10 & -1.0 & 0.63 & 0.140 & -2.45 & 0.41 \\
\hline & Serum & 10 & & & & & \\
\hline \multirow[t]{3}{*}{$\mathrm{NaF}$} & EDTA & 10 & & & & & \\
\hline & $\mathrm{LiH}$ & 10 & 2.1 & 1.07 & 0.079 & -0.30 & 4.53 \\
\hline & Serum & 10 & & & & & \\
\hline \multirow[t]{2}{*}{$\mathrm{LiH}$} & EDTA & 10 & & & & & \\
\hline & $\mathrm{NaF}$ & & & & & & \\
\hline
\end{tabular}

Means difference is significant $\mathrm{p} \leq 0.05,{ }^{*}$ Dependant variable $\mathrm{ACW}(\mu \mathrm{g} / \mathrm{ml})$

Table 3. Comparison between the different media/original values after 2 hour

\begin{tabular}{|lllll|}
\hline Medium & $\mathrm{n}$ & Mean value & $\mathrm{s}$ & $\mathrm{s}_{\mathrm{x}}$ \\
\hline Serum & 10 & 13.3 & 3.92 & 1.24 \\
EDTA & 10 & 6.3 & 3.10 & 0.98 \\
$\mathrm{NaF}$ & 10 & 10.0 & 4.37 & 1.38 \\
$\mathrm{LiH}$ & 10 & 7.9 & 2.72 & 0.86 \\
\hline
\end{tabular}

*Dependant variable ACW $(\mu \mathrm{g} / \mathrm{ml})$

After two hours the results remained the same, the ACW values remained arranged in this order: Serum $>\mathrm{NaF}-$ $\mathrm{LiH}>\mathrm{LiH}>\mathrm{EDTA}$ (Table 1 and 2). By comparing the ACW values with each other it is clear that the ACW values in the Serum tubes were the highest and the ACW values in the EDTA containing tubes were the lowest 


\section{F. M. F. Hayajneh and N. A. Abdellatif}

where the differences were statistically significant in both cases (Table 3). The same results were also achieved after three hours (Tables 5 and 6).

Table 4. Comparison between the different media after 2 hours

\begin{tabular}{|c|c|c|c|c|c|c|c|}
\hline \multirow[t]{2}{*}{ Medium (I) } & \multirow[t]{2}{*}{ Medium (J) } & \multirow[t]{2}{*}{$\mathrm{n}$} & \multirow[t]{2}{*}{ Mean difference $(\mathrm{I}-\mathrm{J})$} & \multirow[t]{2}{*}{$\mathrm{S}_{\mathrm{x}}$} & \multirow[t]{2}{*}{$\mathrm{p}$} & \multicolumn{2}{|c|}{$\begin{array}{l}95 \% \text { Confidence } \\
\text { interval }\end{array}$} \\
\hline & & & & & & Lower limit & Upper limit \\
\hline \multirow{4}{*}{ Serum } & EDTA & 10 & 7.1 & 1.29 & 0.000 & 4.13 & 9.98 \\
\hline & $\mathrm{NaF}$ & 10 & 3.4 & 1.08 & 0.013 & 0.91 & 5.81 \\
\hline & $\mathrm{LiH}$ & 10 & 5.4 & 1.41 & 0.004 & 2.24 & 8.62 \\
\hline & Serum & 10 & & & & & \\
\hline \multirow[t]{3}{*}{ EDTA } & $\mathrm{NaF}$ & 10 & -3.7 & 0.87 & 0.002 & -5.65 & -1.74 \\
\hline & $\mathrm{LiH}$ & 10 & -1.6 & 0.54 & 0.014 & -2.84 & -0.41 \\
\hline & Serum & 10 & & & & & \\
\hline \multirow[t]{3}{*}{$\mathrm{NaF}$} & EDTA & 10 & & & & & \\
\hline & $\mathrm{LiH}$ & 10 & 2.1 & 1.03 & 0.075 & -0.25 & 4.39 \\
\hline & Serum & 10 & & & & & \\
\hline \multirow[t]{2}{*}{$\mathrm{LiH}$} & EDTA & 10 & & & & & \\
\hline & $\mathrm{NaF}$ & 10 & & & & & \\
\hline
\end{tabular}

Means difference is significant $\mathrm{p} \leq 0.05$, Dependant variable ACW $(\mu \mathrm{g} / \mathrm{ml})$

Table 5. Comparison between the different media/original values after 3 hours

\begin{tabular}{|lllll|}
\hline Medium & $\mathrm{n}$ & Mean value & $\mathrm{s}$ & $\mathrm{s}_{\mathrm{x}}$ \\
\hline Serum & 10 & 13.3 & 3.92 & 1.24 \\
EDTA & 10 & 6.3 & 3.10 & 0.98 \\
NaF & 10 & 10.0 & 4.37 & 1.38 \\
LiH & 10 & 7.9 & 2.72 & 0.86 \\
\hline
\end{tabular}

Dependant variable ACW $(\mu \mathrm{g} / \mathrm{ml})$

Table 6. Comparison between the different media after 3 hours

\begin{tabular}{|c|c|c|c|c|c|c|c|}
\hline \multirow[t]{2}{*}{ Medium (I) } & \multirow[t]{2}{*}{ Medium (J) } & \multirow[t]{2}{*}{$\mathrm{n}$} & \multirow[t]{2}{*}{ Mean difference (I-J) } & \multirow[t]{2}{*}{$\mathrm{s}_{\mathrm{x}}$} & \multirow[t]{2}{*}{$\mathrm{p}$} & \multicolumn{2}{|c|}{$\begin{array}{l}95 \% \text { Confidence } \\
\text { interval }\end{array}$} \\
\hline & & & & & & Lower limit & Upper limit \\
\hline \multirow{4}{*}{ Serum } & EDTA & 9 & 8.5 & 1.49 & 0.000 & 5.12 & 11.97 \\
\hline & $\mathrm{NaF}$ & 10 & 3.8 & 0.84 & 0.002 & 1.86 & 5.67 \\
\hline & $\mathrm{LiH}$ & 10 & 6.0 & 1.64 & 0.005 & 2.26 & 9.67 \\
\hline & Serum & 9 & & & & & \\
\hline \multirow[t]{3}{*}{ EDTA } & $\mathrm{NaF}$ & 9 & -4.7 & 0.92 & 0.001 & -6.86 & -2.64 \\
\hline & $\mathrm{LiH}$ & 10 & -2.2 & 0.66 & 0.011 & -3.68 & -0.65 \\
\hline & Serum & 10 & & & & & \\
\hline \multirow[t]{3}{*}{$\mathrm{NaF}$} & EDTA & 9 & & & & & \\
\hline & $\mathrm{LiH}$ & 10 & 2.2 & 1.16 & 0.091 & -0.43 & 4.83 \\
\hline & Serum & 10 & & & & & \\
\hline \multirow[t]{2}{*}{$\mathrm{LiH}$} & EDTA & 10 & & & & & \\
\hline & $\mathrm{NaF}$ & & & & & & \\
\hline
\end{tabular}

"Means difference is significant $\mathrm{p} \leq 0.05,{ }^{*}$ Dependant variable ACW $(\mu \mathrm{g} / \mathrm{ml})$

\section{Centrifugation and time effect on ACW}

Blood samples were taken using Serum tubes and kept in the refrigerator $\left(+4^{\circ} \mathrm{C}\right)$ for 30 minutes. The first measurement of the ACW was possible after one hour because of technical reasons, in two hours interval a blood sample was centrifuged for 10 minutes, $4000 \mathrm{R} / \mathrm{min}$ and the water soluble antioxidative capacity was measured to 
test the stability of ACW. As seen in Tables 7 the ACW values ranged from $11.1 \mu \mathrm{g} / \mathrm{ml}$ after one hour to 10.2 $\mu \mathrm{g} / \mathrm{ml}$ in the samples tested after 6 hours. The difference was statistically not significant (Table 8).

Table 7. Comparison of the ACW stability within 6 hours/ original values

\begin{tabular}{|l|l|l|l|l|}
\hline Time & $\mathrm{n}$ & Mean value & $\mathrm{s}$ & $\mathrm{s}_{\mathrm{X}}$ \\
\hline 1 & 10 & 11.1 & 4.40 & 1.39 \\
\hline 2 & 10 & 10.9 & 4.39 & 1.39 \\
\hline 4 & 10 & 10.8 & 4.24 & 1.34 \\
\hline 6 & 10 & 10.2 & 4.70 & 1.49 \\
\hline
\end{tabular}

${ }^{*}$ Dependant variable ACW $(\mu \mathrm{g} / \mathrm{ml})$

Table 8. Comparison of the ACW stability within 6 hours

\begin{tabular}{|c|c|c|c|c|c|c|c|}
\hline Time (I) & Time (J) & $\mathrm{n}$ & $\begin{array}{l}\text { Mean difference } \\
(\mathrm{I}-\mathrm{J})\end{array}$ & $\mathrm{S}_{\mathrm{X}}$ & $\mathrm{p}$ & \multicolumn{2}{|c|}{$\begin{array}{l}\text { 95\% Confidence } \\
\text { interval }\end{array}$} \\
\hline \multirow{4}{*}{1} & & & & & & Lower limit & Upper limit \\
\hline & 2 & 10 & 0.2 & 0.22 & 0.387 & -0.30 & 0.71 \\
\hline & 4 & 10 & 0.3 & 0.37 & 0.369 & -0.49 & 1.18 \\
\hline & 6 & 10 & 1.0 & 0.35 & 0.024 & 0.16 & 1.76 \\
\hline \multirow{2}{*}{2} & 1 & 10 & & & & & \\
\hline & 4 & 10 & 0.1 & 0.22 & 0.530 & -0.36 & 0.65 \\
\hline \multirow{4}{*}{4} & 6 & 10 & 0.8 & 0.32 & 0.044 & 0.03 & 1.48 \\
\hline & 1 & 10 & & & & & \\
\hline & 2 & 10 & & & & & \\
\hline & 6 & 10 & 0.6 & 0.49 & 0.245 & -0.50 & 1.71 \\
\hline \multirow{3}{*}{6} & 1 & 10 & & & & & \\
\hline & 2 & 10 & & & & & \\
\hline & 4 & 10 & & & & & \\
\hline
\end{tabular}

${ }^{*}$ Means difference is significant $\mathrm{p} \leq 0.05,{ }^{*}$ Dependant variable ACW $(\mu \mathrm{g} / \mathrm{ml})$

\section{Discussion}

Serum tubes do not contain an anticoagulant, the results showed no significant decrease in the ACW values within three hours. A decrease might have happened in the first hour before the ACW values were measured, because it is well known that antioxidants, especially ascorbic acid which comprises a part of the water soluble antioxidants are sensitive to light.

As $\mathrm{NaF}$ has a toxic effect, the $\mathrm{NaF}$ tubes contained also $\mathrm{LiH}$ which has an anticoagulant effect which might play a role together with the toxic effect of $\mathrm{NaF}$ in paralysing red blood cells. The action of red blood cells on the antioxidants present in the sample stoped, which appear later in the test, where the values achieved using these tubes come in the second place after Serum and NaF-LiH tubes.

$\mathrm{LiH}$ on the other hand acts as anticoagulant that gives red blood cells the chance to live longer than in Serum tubes, during this time they consume antioxidants which might be the reason why the results using these tubes are lower than in Serum tubes. In Human medicine EDTA which is an acid containing four carboxylic acid groups, and two amine groups with ion-pair electrons that chealate calcium, and several other metal ions. Calcium is important for a wide range of enzyme reactions of the coagulation cascade, and its removal irreversibly prevent blood clotting within the collection tubes, through this action of EDTA on red blood cells the red blood cells have the chance to live longer, and consume the antioxidants. Before the samples are tested.Plasma tubes were used for the determination of the antioxidative capacity from human blood by (Popov and Lewin, 2000) using the Photochem. Whereas by spectrophotometry method blood samples were kept in heparin containing tubes to determine the antioxidative capacity from mares (Gorecka et al., 2002).Tubes containing ethylenediamine-tetraacetic acid dipotassium salt (EDTA-K2) were used by (Rezaeiand Naghdeh, 2006) to evaluate the antioxidant status and antioxidative stress in cattle naturally infected with Theileriaannulata. 


\section{F. M. F. Hayajneh and N. A. Abdellatif}

It is not advised to use EDTA containing tubes because of the low measured ACW values, it is advised to use Serum tubes for the purpose of measuring the water soluble antioxidative capacity, as a second choice NaFLiH, and $\mathrm{LiH}$ has the advantage, that mostly it needs to be centrifuged only one time. $\mathrm{LiH}$ is used as the medium of choice, because the samples are tested immediately, but in case of veterinary medicine, immediate test of samples is not possible, because samples taken by veterinarians in the field need to be transported to the laboratory first, for this reason it is better to use Serum samples kept under low temperatures (lower than $-20^{\circ} \mathrm{C}$ ).

Regarding the effect of centrifugation on the stability of water-soluble antioxidative capacity, the results showed that the ACW values of blood samples kept in Serum tubes without centrifugation are stable within 6 hours. Red blood cells take antioxidants and die in the samples kept in Serum tubes, and through this action, antioxidants are protected from the effects of light, temperature, but after centrifugation these antioxidants are released once again to be measured by the Photochem.

\section{REFERENCES}

1. Berger LL (2003). Selenium and vitamin E-Antioxidants for animals. http://www.saltinstitute.org/publications/stm/stm-fall-2006.pdf.

2. Bernabucci U, Ronchi B, Lacetera B and Nardone A (2005). Influence of Body Condition Score on Relationships between Metabolic Status and oxidative Stress in Periparturient Dairy Cows. Journal of Dairy Science 88: 2017.

3. Cadenas E and Packer P (2002). Hand book of antioxidants. $2^{\text {nd }}$ edition revised and expanded, Marcel Dekker, New York p. 549.

4. Cao G and Prior LR (1998). Comparison of different analytical methods for assessing total antioxidant capacity of human Serum. Clinical Chemistry 44 (6): 1309-1315.

5. Gorecka R, Kleczkowski M, Klucinski W, Kasztelan R and Sitarska E (2002). Changes in antioxidant components in blood of mares during pregnancy and after foaling. Bulletin of the Veterinary Institute in Pulawy 46: 301-305.

6. Halliwell B and Gutteridge JMC (1984). Oxygen toxicity, oxygen radical, transition metals and disease. Biochemical Journal, 219: 1-14.

7. Kirk RM and Ronald PM (1987). Concentration of ascorbic acid in the blood of cows with subclinical mastitis. Polish Journal of Veterinary Science 8: 121-125.

8. Kleczkowski M, Klucinski W, Shaktur A and Sikora J (2005). Free Radical Metabolite of Uric Acid. The Journal of Biological Chemistry263 4: 1709-1712.

9. Maples KR and Mason RP (1988). Free Radical Metabolite of Uric Acid. The Journal of Biological Chemistry 263 4: 179- 1712.

10. Percival (1996). Antioxidants. NUT031 1/96 Rev. 10/98 Clinical Nutrition Insights, Advanced Nutrition Publications, Inc.

11. Popov I and Lewin G (2000). PhotosensibilisierteChemolumineszenzbei der Quantifizierung von Antioxidantien. BIO Forum 1-2: 46-48.

12. Powers SK and Lennon SL (1999). Analysis of cellular responses to free radicals: focus on exercise and skeletal muscle. Proceedings Of The Nutrition Society 58: 1025-1033.

13. Rezaei SA and Naghdeh BD (2006). Evaluation of antioxidant status and oxidative stress in cattle naturally infected with Theileriaannulata. Veterinary Parasitology 142: 179-186.

14. Ricardo HC, Contreras PA and Wittwer FG (2002). Pathogenesis of oxidative stress: Consequences and evaluation in animal health. Veterinaria Mexico 33(3): 265-283.

15. WEISS WP (2005). Antioxidant nutrients, cow health, and milk quality. Pennsylvania State Dairy Cattle Nutrition Workshop p. 11-18.

16. Yu BP (1994). Cellular defences against damage from reactive oxygen species. Physiological Reviews 74: 139-162. 